\title{
The retinol requirements of rats for spermatogenesis and vision
}

\author{
By W. A. COWARD,* J. McC. HOWELL, J. N. THOMPSON† \\ AND G. A. J. PITT \\ Departments of Biochemistry and Veterinary Pathology, \\ University of Liverpool
}

(Received 27 November 1968-Accepted 3r March 1969)

\begin{abstract}
I. Hooded rats were fed from weaning on a basal retinol-deficient diet containing retinoic acid. Such a diet maintains growth and general health but does not prevent the appearance of lesions associated with vitamin $A$ deficiency in the retina and testis. Some animals were also given supplements of retinol averaging $0.1,0.25$, I or $5 \mu$ g retinyl acetate per day. Rats were killed at intervals up to 28 weeks after weaning. The weights of the testes and the histological appearance of the testes and epididymides indicated that $5 \mu \mathrm{g}$ retinyl acetate per day had maintained spermatogenesis throughout the experimental period. Doses averaging $1 \mu \mathrm{g}$ retinyl acetate per day were only partially effective and the two smaller doses had little beneficial effect.

2. In a second similar experiment rats were given doses of retinyl acetate averaging 0.25 , $0.5,1,2$ or $100 \mu \mathrm{g}$ per day. Measurements of the electroretinogram thresholds of the rats indicated that a dose of I $\mu \mathrm{g}$ retinyl acetate per day maintained mainly normal vision until the end of the experiment 29 weeks after weaning. Additional histological observations made 2 I weeks after weaning showed that this dose level had not maintained spermatogenesis but that doses of $2 \mu \mathrm{g}$ retinyl acetate per day had been effective.

3. The experiments show that the differing functions of vitamin $A$ in spermatogenesis and vision are reflected in the hooded rat in differences in the dietary retinol levels needed to maintain these processes.
\end{abstract}

Rats on a diet free from retinol (vitamin $A$ alcohol) but containing retinoic acid (vitamin A acid) do not develop overt signs of vitamin A deficiency (Arens \& van Dorp, I946) but they become blind (Dowling \& Wald, 1960) and they are unable to reproduce (Thompson, Howell \& Pitt, 1964). The defects in vision and reproduction can be prevented by adding retinol to such a diet.

The amount of retinol required by these animals for normal vision and reproduction cannot be predicted from the total vitamin $A$ requirement as measured by orthodox methods, for retinoic acid in meeting a large part of this need for vitamin A could have a substantial 'sparing effect' on the utilization of retinol.

The only measurements reported on the retinol requirements of rats maintained with retinoic acid were made on pregnant rats by Thompson et al. (1964). Daily doses of $0.5 \mu \mathrm{g}$ retinyl acetate (vitamin $\mathrm{A}$ acetate) during pregnancy enabled rats to produce litters; larger quantities were required for survival of the pups; smaller quantities had an effect on the course of pregnancy in that they prevented absorption of foetuses but all foetuses were born dead.

In the present paper we investigate the effects of graded levels of dietary retinol on vision and spermatogenesis in rats maintained on retinoic acid.

* Present address: M. R. C. Child Nutrition Research Unit, P.O. Box 705 I, Kampala, Uganda.

$\uparrow$ Present address; Department of Poultry Science, Cornell University, Ithaca, NY 14850 , U.S.A. 
EXPERIMENTAL

\section{Animals, diets and supplements}

Hooded male rats were bought as $2 \mathrm{I}$-day-old weanlings weighing $40-60 \mathrm{~g}$; throughout the experiments they were fed on the vitamin A-deficient diet II of Thompson et al. (1964), either with or without supplements of retinoic acid or methyl retinoate.

Supplements of retinoic acid or methyl retinoate were mixed into the diet at a level of $3 \mu \mathrm{g} / \mathrm{g}$ diet. Supplements of retinyl acetate in $0.2 \mathrm{ml}$ arachis oil were given orally, by pipette, three times weekly.

\section{Examination of tissues and histology}

Rats were killed by chloroform inhalation. Testes and epididymides were carefully removed, the testes weighed and one testis and the corresponding epididymis from each rat were fixed in Bouin's fluid for subsequent histological examination. The tissues were embedded in paraffin wax, cut at $4 \mu \mathrm{m}$ and stained with haematoxylin and eosin.

The histological observations on the testes were evaluated as described previously (Coward, Howell, Pitt \& Thompson, I966). Testes were classified according to their histological appearance into five categories, A, B, C, D and E, defined as follows.

Type A: Complete spermatogenesis in all tubules.

Type B: Complete spermatogenesis in most tubules; a few tubules lacked spermatids and spermatocytes.

Type C: Many of the tubules showed complete spermatogenesis; some contained early spermatid stages and in a few there was a severe loss of germinal epithelium.

Type D: There was a severe loss of germinal epithelium. Many of the tubules were lined with Sertoli cells and spermatogonia. In some tubules spermatocytes were numerous but few spermatids were present. Some tubules did not have a lumen and the cytoplasm lining many of the tubules was vacuolated.

Type E: Most of the tubules were lined by Sertoli cells and spermatogonia; spermatocytes were rare and spermatids absent. Some tubules did not have a lumen and the cytoplasmic lining of others was vacuolated. (For photomicrographs illustrating these types, see Coward et al. 1966.)

The epididymides were similarly classified according to their histological appearance. The five categories were as follows.

Type A: Full of sperm.

Type B: Full of sperm; a few sloughed cells were intermingled.

Type C: Many sperm; many sloughed cells were intermingled.

Type D: Many sloughed cells; a few sperm were present.

Type E: No sperm; sloughed cells and eosinophilic material were sometimes present.

Full descriptions of the histological picture of the testes and epididymides of retinol-deficient rats maintained on retinoic acid have been published previously (Howell, Thompson \& Pitt, 1963; Coward et al. 1966). 


\section{Measurement of electroretinogram threshold}

Increasing blindness in rats maintained with retinoic acid is associated with a reduction in the amplitude of the electroretinogram and light of higher than normal intensity is required to obtain a detectable response from these animals. This change in electroretinogram (ERG) threshold can be used as a measure of the visual failure (Dowling \& Wald, I958, 1960).

The electroretinogram was produced and assessed as described elsewhere (Morgan \& Thompson, 1966). The minimum light intensity that could be used to produce a detectable current was considered to be the threshold. A logarithmic scale of light intensity was used and the minimum threshold value obtained on normal rats was arbitrarily given the value 0 . All other intensities were measured as multiples of this minimum light intensity in steps of $0 \cdot 2 \log$ units.

\section{Design of experiments}

Weanling male rats were separated into six groups of nine rats each. One group (I) received a diet completely free from vitamin $A$, and the onset of vitamin A-deficiency signs in these animals indicated the time at which the body stores of the vitamin acquired before weaning were exhausted. They ceased to gain weight and died or were killed during the $4^{\text {th }}$ and $5^{\text {th }}$ weeks after weaning; post-mortem and histological examinations were carried out.

Rats in the other five groups (2-6) were fed a vitamin A-deficient diet supplemented with methyl retinoate. From 12 days after weaning rats in four of the groups (3-6) were also fed retinyl acetate; rats in the remaining group (2) received no retinyl acetate. The treatments were continued until the end of the experimental period 28 weeks after weaning. Rats in the various groups received retinyl acetate averaging the following per day: group 3, O. I $\mu$ g; group 4, 0.25 $\mu \mathrm{g}$; group $5, \mathrm{I} \mu \mathrm{g}$; group 6, $5 \mu \mathrm{g}$.

One rat from each of groups 2-6 was killed 4, 7, 9, 12, I6 and 20 weeks after weaning. Five rats became ill from various causes unconnected with the experiment and were withdrawn from the groups. All healthy rats remaining were killed 28 weeks after weaning.

In the second experiment fifty-three rats were allocated to seven groups at weaning. One group of five rats (group 7) was fed a vitamin A-deficient diet. They all showed signs of deficiency $3 \mathrm{I}$ days after weaning when they were killed and examined.

Rats in the six other groups (eight rats in each) were fed a vitamin A-deficient diet supplemented with retinoic acid. From 16 days after weaning rats in five of the groups were fed retinyl acetate; rats in the remaining group (group 8) received no retinyl acetate supplements. The treatments were continued until the end of the experimental period, 29 weeks after weaning. Rats in the various groups received retinyl acetate averaging the following amounts per day: group 9, $0.25 \mu \mathrm{g}$; group Io, $0.5 \mu \mathrm{g}$; group I I, I $\mu$ g; group I2, $2 \mu \mathrm{g}$; group I3, 100 $\mu \mathrm{g}$.

ERG threshold measurements were made throughout the experimental period; 2I weeks after weaning two rats from group II, five rats from group I2 and three rats from group I 3 were killed for examination of their reproductive organs. 


\section{RESULTS}

Rats in group I, fed diets completely devoid of vitamin A, showed signs of deficiency between 4 and 5 weeks after weaning. Macroscopic evidence of deficiency included enlarged salivary glands, distended stomachs and caeca and bluish, oedematous testes. Histological examinations of the salivary glands showed squamous metaplasia and keratinization of the ducts; in the testes, lesions typical of avitaminosis A were seen: in many tubules the number of spermatids was reduced and many sloughed cells were

Table 1. Effect of various dose levels of retinyl acetate on maintenance of spermatogenesis in rats fed a vitamin A-deficient diet supplemented with methyl retinoate



* Histology classified A (normal)-E (grossly abnormal); for details, see p. 620 . 
present in the epididymides. Similar observations were made on the rats in group 8 , killed after $3^{\mathrm{I}}$ days' feeding on the vitamin A-deficient diet.

Observations made on rats fed the vitamin A-deficient diet supplemented with methyl retinoate are summarized in Table $\mathbf{I}$.

The testes of rats were normal in all groups examined 4 weeks after weaning. The presence of many sloughed cells in the epididymides of these rats was considered to be due to immaturity rather than to an early degenerative change in the testes. The weights of the testes were all similar. Observations made later in the experiment illustrate the progressive degeneration in the testes of rats in groups 2,3 and 4 receiving respectively no retinyl acetate and the equivalent of 0.1 and $0.25 \mu \mathrm{g}$ retinyl acetate

Table 2. Effect of doses averaging $\mathrm{I}, 2$ and $\mathrm{I} 0 \mathrm{\mu g}$ retinyl acetate per day on the maintenance of spermatogenesis in individual rats fed a vitamin A-deficient diet, supplemented with retinoic acid-2I weeks after weaning

\begin{tabular}{|c|c|c|c|c|c|}
\hline \multirow[b]{2}{*}{ Group } & \multirow{2}{*}{$\begin{array}{l}\text { Supplement of } \\
\text { retinyl acetate } \\
(\mu \mathrm{g} / \text { day })\end{array}$} & \multirow[b]{2}{*}{ Body-weight (g) } & \multirow[b]{2}{*}{ Testes weight $(\mathrm{g})$} & \multicolumn{2}{|c|}{ Histological classification* } \\
\hline & & & & Testis & Epididymis \\
\hline I I & I & $\begin{array}{l}400 \\
389\end{array}$ & $\begin{array}{l}0.986 \\
r .469\end{array}$ & $\begin{array}{l}\mathrm{D} \\
\mathrm{D}\end{array}$ & $\begin{array}{l}\mathbf{E} \\
\mathrm{E}\end{array}$ \\
\hline 12 & 2 & $\begin{array}{l}416 \\
410 \\
421 \\
404 \\
427\end{array}$ & $\begin{array}{l}2 \cdot 496 \\
2 \cdot 378 \\
2 \cdot 249 \\
2 \cdot 410 \\
2 \cdot 666\end{array}$ & $\begin{array}{l}\mathrm{A} \\
\mathrm{A} \\
\mathrm{A} \\
\mathrm{A} \\
\mathrm{A}\end{array}$ & $\begin{array}{l}\mathbf{A} \\
\mathbf{B} \\
\mathbf{A} \\
\mathbf{B} \\
\mathbf{A}\end{array}$ \\
\hline I3 & 100 & $\begin{array}{l}398 \\
405 \\
419\end{array}$ & $\begin{array}{l}2 \cdot 761 \\
2 \cdot 242 \\
2 \cdot 735\end{array}$ & $\begin{array}{l}\mathrm{A} \\
\mathrm{A} \\
\mathrm{B}\end{array}$ & $\begin{array}{l}\mathrm{A} \\
\mathrm{A} \\
\mathrm{A}\end{array}$ \\
\hline
\end{tabular}

* Histology classified A (normal)-E (grossly abnormal); for details see p. 620 .

per day. While I $\mu$ g retinyl acetate per day was not adequate for the maintenance of spermatogenesis throughout the experimental period, it was effective up to I 6 weeks after weaning. This dose level is apparently only slightly below that required to maintain spermatogenesis. Rats in group 6 , receiving the equivalent of $5 \mu$ g retinyl acetate per day, had normal testes throughout the experimental period.

In the second experiment doses averaging $\mathrm{I} \mu \mathrm{g}$ retinyl acetate per day (group I I) were shown to be inadequate for the maintenance of spermatogenesis $2 \mathrm{r}$ weeks after weaning; whereas doses averaging 2 and $100 \mu \mathrm{g}$ retinyl acetate per day (groups $\mathrm{I} 2$ and 13 ) were adequate up to this time (see Table 2).

Experiments on the requirements of retinol for vision were not as conclusive (see Table 3). The high threshold values obtained with young rats were probably due to the small size of the animals, which reduces the efficiency in detecting small responses. The results in Table 3 indicate that supplementation with $\mathrm{I} \mu \mathrm{g}$ retinyl acetate per day (group II) prevented any marked increase in the electroretinogram threshold above that of the controls given $100 \mu \mathrm{g}$ retinyl acetate daily (group $\mathrm{I}_{3}$ ) and certainly appeared no less effective than a dose of $2 \mu \mathrm{g}$ retinyl acetate (group 12 ). Supplements of $0.5 \mu \mathrm{g}$ (group 10) and $0.25 \mu \mathrm{g}$ (group 9) failed to maintain normal vision but merely delayed the rise in threshold relative to the unsupplemented animals (group 8). 
The effectiveness of I $\mu$ g retinyl acetate per day in vision (Table 3 ) contrasts with its failure to maintain spermatogenesis (Tables $I$ and 2) and demonstrates that, in hooded rats maintained on retinoic acid, the requirement of retinol for spermatogenesis is higher than that for vision.

Table 3. Changes in electroretinogram threshold in rats fed a vitamin A-deficient diet supplemented with retinoic acid and various amounts of retinyl acetate

$\begin{array}{ccccccc}\text { Group } \ldots & 8 & 9 & \text { ro } & \text { I I } & 12 & 13 \\ \begin{array}{c}\text { Retinyl acetate } \\ \text { supplement/day }\end{array} & 0 & & & & \\ (\mu \mathrm{g}) \ldots & 0 & 0.25 & 0.5 & 1 \cdot 0 & 2 \cdot 0 & 100\end{array}$

Days on diet Increase of threshold (log units of luminance) above minimum in normal rats

$\begin{array}{lllllll}33 & - & 0.8 & 0.8 d & 0.6 g & 0.6 l & 0.8 p \\ 40 & - & - & 0.6 e & 0.6 h & 0.6 m & 0.6 \\ 48 & 0.8 & - & 0.6 f & - & 0.2 n & 0.2 q \\ 50 & - & - & - & 0.8 i & - & - \\ 57 & 2.0 & 1.0 b & 0.4 & 0.6 j & - & 0.2 \\ 64 & 1.6 & 1.0 & 0.2 d & 0.0 h & 0.2 & 0.6 \\ 93 & 1.8 a & 0.4 & 0.0 f & 0.0 & 0.0 & 0.0 \\ 142 & 1.6 & 1.4 c & 0.6 & 0.2 k & 0.20 & 0.0 r \\ 147 & - & - & - & 0.4 g & 0.6 n & 0.0 p \\ 147 & - & - & - & 0.6 j & 0.2 l & 0.2 r \\ 147 & - & - & - & - & 0.4 & 0.4 q \\ 147 & - & - & - & - & 0.6 o & - \\ 147 & - & - & - & - & 0.4 m & - \\ 196 & - & - & 1.6 & - & - & - \\ 196 & - & - & 0.8 & - & - & - \\ 196 & - & - & 0.8 c & - & - & - \\ 204 & 3.0 a & 2.0 c & 1.4 & 0.2 k & -\end{array}$

Some of the above measurements were made on the same rat at two different times; the suffixes indicate such rats, designated $a-r$.

\section{DISCUSSION}

In rats fed a vitamin A-deficient diet vitamin A is lost from the liver stores and retinaldehyde from the retina; Dowling \& Wald (1960) showed that supplementing such diets with retinoic acid did not diminish the rates at which these tissues were depleted. Our results here also indicate that feeding with retinoic acid has no sparing effect on the utilization of small quantities of dietary retinol. Even though in the present experiments ample retinoic acid was given to cover all requirements for vitamin A other than in vision or reproduction, the amount of retinyl acetate required for the maintenance of spermatogenesis-more than I $\mu \mathrm{g}$ and about $2 \mu \mathrm{g}$ per day-is higher than that required to promote growth on a diet completely deficient in vitamin A (Moore, 1957). The dose of retinol that had to be given to maintain spermatogenesis would have been sufficient to cover most other vital functions - even in the absence of retinoic acid.

The testes, despite their absolute and direct requirement for retinol (Palludan, r966; Coward et al. 1966), appear to have no marked precedence in calling upon limited supplies over other organs capable of using retinoic acid. 
The differing retinol requirements for vision and spermatogenesis in our hooded rats could reflect a more fundamental difference in the way in which the vitamin is used by the eyes and the testes. While little is known about the metabolism of retinol in the testes, the use of retinol in vision is well understood and is suggestive of a degree of economy that might not be encountered elsewhere in the body. Dowling ( 1960 ) has described the events in dark and light adaptation, which result in the reversible conversion and movement of retinaldehyde from the visual pigment into retinyl esters in the pigment epithelium. The eye therefore might maintain to some extent a closed system in its use of vitamin $A$, and the requirement for retinol for vision would then be that needed to replace a small inevitable loss of vitamin due to leakage or chemical change.

Table 3 shows that the rise of visual threshold and hence the loss of vitamin A from the eyes is much less in the hooded rats of these experiments than in the albinos used by Dowling \& Wald (1960). Lewin (1968) has measured the rhodopsin content of hooded rats' eyes and has found that, when the rats were maintained on retinoic acid in the absence of retinol, they lost approximately $0.005 \mu \mathrm{g}$ retinol per rat per day from the eyes. It is possible to calculate the rhodopsin content of the eye from the ERG threshold (Dowling \& Wald, 1958, I960; Lewin, 1968) and although there are not enough results in Table 3 to derive a reliable figure for losses in rats of group 8, calculations indicate that they do not exceed $0.004 \mu \mathrm{g}$ per rat per day. The dietary intake of retinol required to maintain vision in rats maintained on retinoic acid must therefore be at least 200 times greater than the amount the eyes need to take up. Despite its need for retinol and the tenacity with which, in our hooded rats, retinaldehyde is retained in the visual pigment, the eye, like the testis, does not seem to be markedly favoured in obtaining retinol when there is very little available from the diet.

Small quantities of the vitamin are presumably destroyed during absorption and transport to the tissues and, at the very low intake of our experiments, such losses are likely to be proportionately larger and their effects more noticeable than at a more normal dietary level. They are, however, unlikely to be the major cause of the discrepancy between the retinol requirements of tissues which are wholly dependent on it and the dietary intake necessary to satisfy these needs. This discrepancy appears to be inevitable when one considers the transport of retinol to the tissues. Retinol is carried on a specific plasma protein (Glover \& Walker, r964; Kanai, Raz \& Goodman, I968), and the plasma level of vitamin $A$ increases with the dietary intake (Lewis, Bodansky, Falk \& McGuire, 1942). Coward \& Thompson (1967) found that, when small doses of retinol are given to rats maintained on retinoic acid, all tissues take up retinol-even those that apparently have had all their needs for vitamin A met by retinoic acid. The evidence of the present paper indicates that the complete dependence of the testis and eye on retinol does not cause retinol to be preferentially diverted into them. 'The apparently supererogatory uptake of retinol by other tissues is probably the major cause of the discrepancy between the retinol content of the diet and the actual requirements of tissues such as the eye and the testis in the conditions of our experiments. The inability of retinoic acid to prevent this uptake by other tissues explains its failure to spare retinol. 
We wish to thank Dr O. Isler of F. Hoffman-La Roche \& Co., Basel, for gifts of retinoic acid, and Mrs M. W. Harling, AIMLT, and Mrs D. Phethean for technical assistance. The work was supported in part by United States Public Health Service Grant AM-05282-04. W.A.C. was in receipt of an Agricultural Research Council Research Studentship and J.N.T. was a British Egg Marketing Board Fellow.

\section{REFERENCES}

Arens, J. F. \& van Dorp, D. A. (1946). Nature, Lond. 157, r9o.

Coward, W. A., Howell, J. McC., Pitt, G. A. J. \& Thompson, J. N. (r 966). F. Reprod. Fert. I2, 309.

Coward, W. A. \& Thompson, J. N. (1967). Biochem. F. 103, 35 P.

Dowling, J. E. (1960). Nature, Land, 188, i r4.

Dowling, J. E. \& Wald, G. (1958). Proc. natn. Acad. Sci. U.S.A. 44, 648.

Dowling, J. E. \& Wald, G. (1960), Proc. natn. Acad. Sci. U.S.A. 46, 587.

Glover, J. \& Walker, R. A. (I964). Exp. Eye Res. 3, 374.

Howell, J. McC., Thompson, J. N. \& Pitt, G. A. J. (1963). F. Reprod. Fert. 5, 159.

Kanai, M., Raz, M. \& Goodman, D. S. (1968). Y. clin. Invest. 47, 2025.

Lewin, D. R. (I968). Interactions of vitamin A derivatives with opsins. PhD Thesis, University of Liverpool.

Lewis, J. M., Bodansky, O., Falk, K. G. \& McGuire, G. (1942). F. Nutr. 23, 35 I.

Moore, T. (1957). Vitamin A, p. 225. Amsterdam: Elsevier.

Morgan, B. \& Thompson, J. N. (I966). Biochem. f. Ior, 835.

Palludan, B. (1966). Nature, Lond. 211, 639.

Thompson, J. N., Howell, J. McC. \& Pitt, G. A. J. (1964). Proc. R. Soc. B r59, 5 ro. 